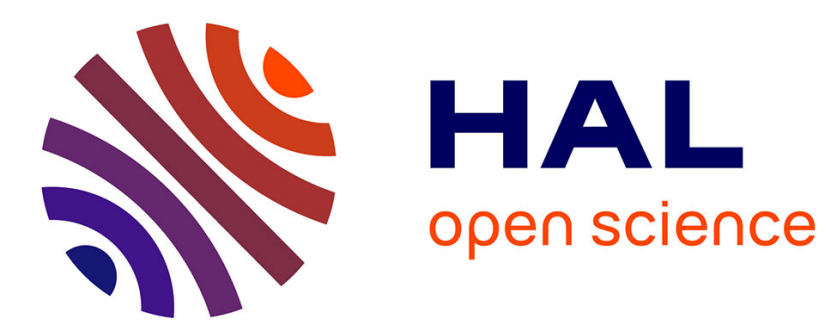

\title{
SURFACE ENHANCED RAMAN SCATTERING : AN OVERVIEW OF EXPERIMENTS
}

\author{
R. Chang
}

\section{To cite this version:}

R. Chang. SURFACE ENHANCED RAMAN SCATTERING: AN OVERVIEW OF

EXPERIMENTS. Journal de Physique Colloques, 1983, 44 (C10), pp.C10-283-C10-294.

10.1051/jphyscol:19831059 . jpa-00223517

\section{HAL Id: jpa-00223517 https://hal.science/jpa-00223517}

Submitted on 1 Jan 1983

HAL is a multi-disciplinary open access archive for the deposit and dissemination of scientific research documents, whether they are published or not. The documents may come from teaching and research institutions in France or abroad, or from public or private research centers.
L'archive ouverte pluridisciplinaire HAL, est destinée au dépôt et à la diffusion de documents scientifiques de niveau recherche, publiés ou non, émanant des établissements d'enseignement et de recherche français ou étrangers, des laboratoires publics ou privés. 


\title{
SURFACE ENHANCED RAMAN SCATTERING : AN OVERVIEW OF EXPERIMENTS
}

\author{
R.K. Chang \\ Yale University, Section of Applied Physics and Center for Laser Diagnostics, \\ New Haven, Connecticut 06520,U.S.A.
}

\begin{abstract}
Résumé - Les aspects expérimentaux de 1 'effet Raman exalté de surface sont brièvement passés en revue avec des expériences démontrant les mëcanismes d'excitation électromagnétique et de transfert de charge, en insistant sur les mécanismes d'exaltation. Le manque de données quantitatives sur le recouvrement moléculaire sur des sites de surface spécifiques est discutê, ainsi que la nécessité de corréler les résultats de 1 'effet Raman exalté de surface avec d'autres données de physique des surfaces.
\end{abstract}

Abstract - Experimental aspects of surface enhanced Raman scattering (SERS) are briefly reviewed with experiments demonstrating electromagnetic and charge-transfer excitation, enhancement mechanisms being specifically noted. The lack of quantitative data on molecular coverage at specific surface sites is discussed, as well as the need to correlate SERS results with other surface physics sensitive data.

\section{I - INTRODUCTION}

An overview of the experimental status of surface enhanced Raman scattering (SERS) is simplified because of several in-depth review articles published prior to 1983 [1-4] or soon to be published [5-8]. Sumarized here are some of the wel1 accepted experimental observations, remaining controversies which still challenge experimentalists, and finally several results obtained by other surface physics techniques which relate closely to the overall understanding of SERS mechanisms. An overview of the current theoretical status of SERS can be found in Ref. 9.

The most accepted experimental fact is that some form of surface roughness increases the detected Raman signal. This roughness could be created by various types of processes, such as: (1) electrochemical - oxidation and reduction of the electrode [1-3,7,8] or plating of the metallic ions in the electrolyte [10]; (2) photochemica1 - photoreduction of adsorbates on electrodes [11], single crystals [12], or powder surfaces [13]; (3) evaporation - vacuum deposition of metallic films on smooth insulating or metallic substrates [14], or on already roughened insulating or metallic island substrates $[15,16]$; (4) 1ithography - grating structures on Ag surfaces [17] or uniformly shaped Ag microstructures on an array of $\mathrm{SiO}_{2}$ posts [5,18]; (5) chemical reduction - metallic colloids produced in aqueous solution $[2,4,19]$, (6) vapor deposition - c1usters of a few metal atoms surrounded by a matrix [20]; and (7) mechanical polishing - use of different sized abrasives [21].

Many of the currently existing controversies stem from the experimentalists' ignorance of the complete surface topology. Conventional scanning electron microscopy (SEM), having $200 \AA$ resolution, can easily be used to characterize the topology of roughened surfaces without much sample preparation. Therefore, much of the existing literature describes attempts to correlate $\geq 200 \AA$ topology to SERS results. Along with these $\geq 200 \AA$ structures, submicroscopic (e.g., in the size range。 $20-200 \AA$ ) and even atomic scale roughness (e.g., from a single atom to $20 \AA$ ) can also exist. Isolated submicroscopic structures (e.g., spheres and spheroids) are known classically to produce large electromagnetic intensity on the surface when 
the incident or scattered photon energy is in resonance with the localized surface plasmon resonance [22]. The atomic scale roughness (e.g., a single adatom or clusters of a few adatoms) is known quantum mechanically to enhance the Raman polarizability in two ways [7]; (1) to increase the photon-free electron coupling because of relaxation of the momentum selection rule; and (2) to induce chargetransfer surface energy levels if chemisorption exists between the adsorbed molecule and the metal atomic scale roughness; resonance Raman effect can therefore be achieved when the incident or scattered photon energy is equa1 to the energy difference between the charge-transfer and Fermi levels. Thus, accurate characterization of the $\leq 200 \AA$ surface topology is essential to unraveling the quantitative importance of the "classical" vs "chemical" mechanisms. Conventional transmission electron microscopy (TEM), having $10 \mathrm{~A}$ resolution, can be readily used to characterize colloids but is not usable for solid surfaces or films coated on thick substrates. Only recently, Ag island films (with or without $\mathrm{Au}$ or Ni decorations) coated on especially prepared thin substrates have been characterized by TEM with better than $10 \AA$ resolution [23]. However, some doubt exists as to whether the atomic scale roughness will remain stable when the environmental conditions are changed, e.g., in the transfer from the UHV chamber to the ambient or when the adsorbate coverage is altered. Consequently, unless in-situ TEM characterization can be made, the correlation of SERS to atomic scale roughness must rely on more indirect means. The future experimental challenge is to devise other techniques sensitive to the distributions in the surface morphology which can be employed while SERS measurements are being taken. Some recent1y developed techniques particularly sensitive to atomic scale roughness will be noted here. As SERS is sensitive to surface morphology characteristics and to a lesser extent to specific types of adsorbed molecules, results obtained using different types of surface roughness will be presented. In addition, recent advances in Raman instrumentation will be summarized.

\section{INSTRUMENTATION ADVANCEMENT}

The replacement of the conventional double monochromator and a photomultiplier with a triple-stage spectrograph and a multi-element quantum-noise-1imited detector is now possible with commercially available instrumentation [24]. Replacing the former single-channel analyzer (SCA) with the optical multichannel analyzer (OMA) has enabled simultaneous measurement of the temporal evolution of many SERS peaks and the broad background with W $\mathrm{s}$ time resolution as the potential of the electrochemical cell is varied $[25,26]$. If the SERS signal is large enough, present1y available multi-element detectors (SIT or linear-array photodiodes) can complete a total spectral scan every $1 / 30 \mathrm{~s}$ or even faster. In addition to temporal measurements, the OMA equipped with a two-dimensional detector (e.g., an SIT tube and optical microscope) has been used to map out active and inactive SERS areas on a Ag electrode (with spatial resolution better than $4 \mathrm{jm}$ ) [27]. In fact, by using a two-dimensional detector and triple-stage spectrograph, which can preserve the spatial integrity of a line image formed at its entrance slit, the experimentalist can monitor the temporal evolution of the SERS spectra (e.g., dispersed along the $x$-axis) from many points along a line illuminated on the surface (e.g., spatially preserved along the $y$-axis).

Another contribution of the OMA to the SERS field is its greatly improved signalto-noise ratio when compared with that of the SCA. By accumulating the weak Raman signal on the essentially noise-free, single-photoelectron sensitive target until the total charge per spectral channel is large enough to overcome the electronic noise introduced by the read mode, the OMA is capable of measuring a Raman spectrum below the limits of the SCA (as much as $10^{3}-10^{4}$ times [24]). Consequently, experimentalists need not just measure the "tip of the iceberg" (i.e., the last $10^{2}$ enhancement of the total $10^{5}-10^{7}$ enhancement) but, in principle, can monitor the entire enhancement from various mechanisms, beginning with no enhancement on a flat metallic surface and following the enhancement as the different sizes of roughness are produced. In fact, Raman scattering from monolayers of molecules placed on surfaces without SERS conditions has already been reported (e.g., on low-index faces of Ag crystals [28] and on smooth $1000 \AA$ thick Al surface 
films [29]). The improved signal-to-noise ratio and faster data-gathering speed are apparent when comparing OMA spectra [28,29] with SCA spectra from "smooth" but not necessarily perfectly smooth Ag surfaces $[21(b), 30]$.

\section{III - SERS RESULTS}

(a) Colloids

In principle, colloids in aqueous solution are ideal for testing the validity of the classical electromagnetic enhancement mechanism since, according to TEM micrographs, the colloids are nearly spherical in shape, sma11 ( $400 \AA$ in diameter), and nonaggregated. (On1y 3\% form aggregates of 2 or more colloids [31].) Such a collection of $\mathrm{Ag}$ or $\mathrm{Au}$ colloids is tractable for classical electromagnetic calculations. The extinction, elastic scattering, surface-averaged electric field intensity, and radial component of the electric field intensity can be readily calculated by the Lorena/Mie formalism as a function of sphere diameter and radiation wavelength [32]. For Ag spheres with diameters less than $400 \AA$, al1 these calculable quantities are predicted to exhibit a single sharp peak at the localized surface plasmon wavelength ( $400 \mathrm{~nm}$ for Ag in water [32]). For predominantly nonaggregated colloids, the measured extinction and elastic scattering spectra agreed with the calculations. Surprisingly, the measured SERS excitation spectrum on the same colloids did not agree with the calculated wavelength dependence of the surface-averaged electric field intensity or its radial component $[31,33]$. This discrepancy seems to imply that the observed SERS excitation curve may not be totally associated with the electromagnetic mechanism. However, one group reports that the measured SERS excitation.curve follows the measured extinction spectra, both peaking in the blue and fa11ing in the red [34].

For more aggregated colloids, the measured extinction and elastic scattering exhibited a secondary peak in the red and the measured SERS excitation curve, which still peaked in the red, was explained as being commensurate with the longitudinal surface plasmon resonance related to a chain formed by $2-4$ Ag spheres $[2,19]$. There is agreement that aggregation does increase the SERS signal but controversy exists as to whether aggregated structure is essential for the observation of SERS. At a fixed wavelength $(514.5 \mathrm{~nm})$, the overa11 SERS intensity from fixed numbers of $\mathrm{Ag}$ colloids was found to increase 5 times when the amount of aggregation was deliberately increased from $3 \%$ to more than $90 \%$ by adding $\mathrm{Na}^{+}$ions in the solution [31].

The following questions are being asked regarding the initial assumptions aasumed to be valid for colloids: (1) Is the bulk dielectric constant $\varepsilon(\omega)$ applicable for such small diameter colloids, since landau damping resulting from the more frequent surface scattering will definitely increase the imaginary part of $\varepsilon(\omega)$ and thereby decrease electromagnetic enhancement [35]? (2) Is the surface of the colloids totally devoid of atomic-scale roughness since upon close TEM examination, the Ag colloids consist of crystalline facets joined by sharp borders and corners [3I]? (3) Are the adsorbed molecules uniformly distributed over the colloid spheres since there can be a difference in chemical bonding of molecules with flat facets and with defect sites (including kinks, steps, dislocations, and bumps) [3,7]? (4) Does the adsorbed molecule really sense the external field of an idealized abrupt boundary interface (between the Ag metal and water) since on the atomic scale the normal component of the electromagnetic field can vary rapidly and differs considerably from the classical calculation [36]? (5) When the molecule is located on the surface, is there a short range interaction (e.g., involving tight-binding matrix elements) between the molecule and the metal since the approximation with a classical image dipole (renormalization factor for the Raman polarizability) and with a local $\varepsilon(\omega)$ (screening by the electrons in the metal) is no longer justified [36,37]? In fact, most of these queries are applicable to other metal roughness found on electrodes, lithographically prepared structures, and films. Furthermore, queries (4) and (5) are even pertinent to atomically smooth single-crystal surfaces. All these questions need to be answered quantitatively before the different enhancement mechanisms can be distinctly segregated. 
Even though some skepticism exists about colloids as an ideal test case for the classical electromagnetic enhancement, the fact that the morphology of the colloid can be more easily characterized by TEM than other commonly used SERS media is an appealing factor. At least the experimentalists can know the average submicroscopic shape, size, and separation and can vary the size by preparation techniques and the separation by changing the initlal metal ion concentration in the solution and/or by adding cation concentration to induce aggregation. Furthermore, metals other than $\mathrm{Ag}$, $\mathrm{Au}$, and $\mathrm{Cu}$ can be prepared. For example, an enhancement factor of $\checkmark 7$ was recently reported for Pt (CN) $\frac{2}{4}$ ions adsorbed on $10 \AA$ spherical Pt colloids [38]. The excitation profile peaked at $2400 \mathrm{~nm}$ in fair agreement with that of benzene molecules adsorbed on irregularly shaped Pt particles with sizes in the $100 \AA$ range [39] and with the Lorenz/Mie calculation of the surface-averaged intensity [38].

The ability of Ag colloids to coadsorb optically nonabsorbing molecules (pyridine or citrate) and dye molecules opened up new opportunities to investigate the possibility of surface enhancement of molecules already exhibiting resonance Raman effect [40]. SERS was observed for the optically nonadsorbing molecules $\left(\sim 5 \times 10^{5}\right.$ enhancement factor for pyridine or citrate) but not for the optically absorbing dye molecules (methyl orange, methyl red, or crystal violet). The lack of enhancement for the dye molecules is in direct contradiction to previous reports of enhancement for similar or identical dyes on colloids [41], electrodes [42], wedged $\mathrm{Ag}$ films [43], and island Ag films [44-46]. It should be emphasized that in interpreting the enhancement factor of the discrete inelastic spectrum from optically absorbing molecules the distinction needs to be carefully made among resonant Raman effect, resonant fluorescence, and fluorescence [45]. Furthermore, in analyzing the polarization dependence of the incident and scattered radiation, Franck-Condon matrix elements need to be considered for optically absorbing molecules in addition to the usual classical electromagnetic field distribution on the sphere [19].

Vaporization of $\mathrm{Ag}$ in an argon atmosphere causes small atomic clusters to grow through the thermomolecular processes. These below submicroscopic dimension clusters are swept into a separate chamber where the argon gas is removed and the particles are condensed with $\mathrm{CO}$, ethylene, acetylene, or ethane $[20,47]$. The excitation spectra for the SERS intensity associated with the former three types of molecules increased toward the violet as a function of photon energy (in accordance with the extinction spectra) while no SERS was found for ethane [47]. The lack of SERS for specific molecules implies that for these molecules the "chemical" mechanisms are not contributing and thus the overall enhancement is below the detection threshold used in the investigations. However, the electromagnetic mechanism can still contribute to the overall enhancement.

The presence of monomeric, dimeric, and even trimeric Ag molecules has been deduced from optical absorption measurements [48], along with the Raman spectra of $\mathrm{Ag}_{2}$ and $\mathrm{Ag}_{3}$ clusters which have vibrational frequencies in the $900-1100 \mathrm{~cm}^{-1}$ range [49]. Furthermore, infrared spectra of pyridine-Ag atoms and pyridine-Ag clusters have been observed and thus provide a useful comparison for the SERS studies [50]. The infrared studies indicated that the $992 \mathrm{~cm}^{-1}$ breathing mode of free pyridine molecules is increased to $1000.2 \mathrm{~cm}^{-1}$ when low concentrations of $\mathrm{Ag}$ atoms are deposited. Further increases to $1009.8 \mathrm{~cm}^{-1}$ are observed when the concentration of $\mathrm{Ag}$ atoms is raised. The 1000.2 and $1009.8 \mathrm{~cm}^{-1}$ bands were assigned to pyridine complexes involving a single $\mathrm{Ag}$ atom and a small $\mathrm{Ag}$ cluster (most likely $\mathrm{Ag}_{2}$ ), respectively [50]. These infrared results are in agreement with numerous experimental SERS investigations which showed that the breathing mode increases from $992 \mathrm{~cm}^{-1}$ for physisorbed pyridine to $1005 \mathrm{~cm}^{-1}$ for chemisorbed pyridine with Ag surfaces. This agreement lends support to the importance of atomic scale roughness in enhancing part of the SERS signal and in influencing the pyridine vibrational frequency. The vaporization technique of producing atomic clusters condensed in a matrix of Raman active material is being extended to other metals such as $\mathrm{K}[51]$. 


\section{(b) Regular1y arrayed Ag microstructures}

Ag microstructures (resembling spheroids with $3: 1$ and $2: 1$ aspect ratio) evaporated on regular $\mathrm{SiO}_{2}$ posts with $1000 \AA$ diameter, $5000 \AA$ high, a $\backsim 500 \AA$ A radius of curvature at the tops of the posts, and separation of $3200 \AA$ in a regular square array [18] have been used in order to study the electromagnetic enhancement mechanism. Unlike the colloidal system, each spheroid has nearly uniform shape, size, and separation between the microstructures. However, the dimensions of each of the spheroids (e.g., $2 \mathrm{a}=3000 \AA$ or $2000 \AA$ and $2 \mathrm{~b}=1000 \AA$ ) are much larger than those of the colloids discussed in the previous section. The electrostatic Rayleigh approximation (i.e., within the electric-dipole limit) can no longer be used. Experimentally, the peak of the excitation spectra of the SERS from $\mathrm{Ag}(\mathrm{CN})_{2}$ adsorbed on these microstructures after the entire array was exposed to HCN vapor was found to shift to the red under the following conditions: (1) with increase of aspect ratio from $2: 1$ to $3: 1$; (2) with increase of the dielectric constant of the surrounding medium, e.g., from air $\varepsilon_{\mathrm{O}}=1$, to $\mathrm{H}_{2} \mathrm{O} \varepsilon_{\mathrm{o}}=1.77$, and to cyclohexane $\varepsilon_{0}=2.04$. Although these two results agreed with the general predictions of the electrostatic Rayleigh approximation, the measured linewidth of the excitation peaks was much too broad $(20.4 \mathrm{eV})$. In order to match the experimental results with the Rayleigh results, size-dependent radiation damping effects, interaction among the Ag microstructures, larger imaginary parts of $\varepsilon(\omega)$, and fluctuation in the spheroid $a: b$ ratio have been introduced to improve the inappropriate Rayleigh calculations $[5,18,52]$. Recent exact calculations, using the electrodynamic Lorenz/Mie formalism, were made on the surface-averaged intensity and the intensity at the tips (1ightning-rod effect) for an isolated spheroid of $2 a=2000 \AA$ and $2 \mathrm{~b}=1000 \AA$ and found to be in reasonable agreement with the measured SERS excitation profile, the broad linewidth, and the observed shift to the red with increasing $\mathrm{a}: \mathrm{b}$ ratio and $\varepsilon_{0}$.

The most significant result of this computer intensive electrodynamic calculation is that the electromagnetic enhancement factor is more than two orders of magnitude lower for Ag microstructures with large dimensions and bulk dielectric constants. Consequently, the experimentally deduced $710^{7}$ enhancement factor (for the $2144 \mathrm{~cm}^{-1}$ CN stretching mode) at the peak of the excitation spectrum is erroneous, or other SERS mechanisms, in addition to the electromagnetic mechanism, contribute $210^{3}$ to the overall enhancement factor. Assuming that the latter is true, it can then be deduced from the qualitative agreement between the wavelength dependence of the electromagnetic intensity and the measured SERS excitation spectrum that the other SERS mechanisms have little or no wavelength dependence throughout the visible range. Furthermore, the other SERS mechanisms cannot be influenced by immersion in $\mathrm{H}_{2} \mathrm{O}$ and cyclohexane. Many of the queries raised about colloids also apply here to these regularly arrayed microstructures. Furthermore, it can be speculated that during the HCN exposure some atomic roughness is formed on the Ag microstructure (even if none existed prior to HCN exposure). For example, microscopic bumps on the flat crystalline facets of $\mathrm{Ag}$ granules were produced when the $\mathrm{Ag}$ powder (presumably having a $\mathrm{Ag}_{2} \mathrm{O}$ first layer) was exposed to $\mathrm{NO}_{2}$ gas. Perhaps atomic scale roughness can exist with these newly induced microscopic bumps [13]. However, when similar $\mathrm{Ag}$ powder was exposed to $\mathrm{HCN}$, these microscopic bumps were not observed by SEM [53].

Another important implication from the electrodynamic calculation is that the surface-averaged intensity enhancement factor should be sensitive to the incident polarization, whether it is along the major or minor axis. Experimentally, sample orientation relative to the incident polarization was not found to be a sensitive parameter [18]. Consequently, this observation has cast some doubt on the importance of the electromagnetic mechanism on even these spheroids.

The distance dependence of the electromagnetic intensity away from a large Ag spheroidal surface has not been calculated, although it is predicted to be different from that of a sphere in the Rayleigh 1 imit (i.e., different from the result of $\left|a /(a+d)^{3}\right|^{2}$, where $a$ is the sphere radius and $d$ is the distance from the surface). Nor have spacer experiments been made on these regularly arrayed $\mathrm{Ag}$ microstructures. Such distance-dependence calculations and spacer experiments will 
no doubt be critical to quantifying the magnitude of the classical electromagnetic enhancement for such large microstructures.

In addition to $\mathrm{Ag}$, other metallic microstructures ( $\mathrm{Au}$ and $\mathrm{A} 1$ ) have been evaporated on similar regularly arrayed $\mathrm{SiO}_{2}$ posts [54]. For Au microstructures, the $\mathrm{CN}$ mode temporally evolved from a narrow $2144 \mathrm{~cm}^{-1}$ peak to a broader peak at $2191 \mathrm{~cm}^{-1}$ (implying chemical reaction with the ambient), and the excitation spectrum for the $3: 1$ spheroids exhibited a single peak at $v 640 \mathrm{~nm}$ with narrower linewidth than the corresponding peak at $2540 \mathrm{~nm}$ for 3:1 Ag spheroids. The observed enhancement factor for $\mathrm{Au}$ spheroids was $\sim 5 \times 10^{6}$. For Al microstructures, SERS from a monolayer of p-nitrobenzoic acid was observed with $488 \mathrm{~nm}$ excitation and was found to be only 500 times weaker than the SERS from a similar layer placed directly on the Ag microstructures. Between 564 and $459 \mathrm{~nm}$, the SERS intensity increased by a factor of 3 . However, the $\mathrm{A} 1$ results are complicated by two facts: (1) SEM characterization showed that the shape of the Al particles is different from that of the $\mathrm{Ag}$ or $\mathrm{Au}$ particles. (2) In the laboratory atmosphere, an oxide coating $(\sim 3 \mathrm{~nm})$ existed on the surface of each AI particle. At present, no electrodynamic calculation exists for Au and Al spheroids. Therefore, no comparison between classical electromagnetic theory and experiments can be made. The fact that SERS was observed on A1 [54], especially with a built-in $3 \mathrm{~nm}$ spacer, implies that in the future SERS measurements as a function of spacer thickness may be possible from such regularly arrayed microstructures. Aluminum oxide [55] and $\mathrm{SiO}_{\mathrm{x}}[46$ ] spacer layers have previously been used in $\mathrm{Ag}$ island film studies. Since the nonlinear optical signal has a higher order dependence on the incident field intensity than does SERS [58], simultaneous SERS and surface enhanced nonlinear optical measurements (e.g., second-harmonic generation [56] or hyper-Raman scattering [57]) on $\mathrm{Ag}, \mathrm{Au}$, and $\mathrm{Al}$ microstructures can in the future aid in quantifying the various enhancement processes.

\section{(c) Electrodes}

Most SERS experiments are carried out in an electrochemical cell, and several review papers are available on the electrochemistry associated with the oxidation and reduction cycle (ORC), SERS, and surface enhanced nonlinear optical results [8,59, 60]. There is general agreement about the following processes involved with $\mathrm{Ag}$ electrodes immersed in simple electrolytes (e.g., in alkali-halides or pseudohalides): (1) During the oxidation half cycle, oxidation of the Ag electrode occurs, $\mathrm{Ag}^{\circ} \rightarrow \mathrm{Ag}^{+}+\mathrm{e}^{-}$which can combine with the anions within the solid-1iquid interface (double layer) to form an adsorbate layer which, depending on its solubility and adhesiveness, may or may not adhere to the electrode; the Ag surface is roughened and the amount of $\mathrm{Ag}$ oxidation can be monitored by the total charge passed through the electrode. (2) During the reduction half cycle, the adsorbate layer and some of the $\mathrm{Ag}^{+}$in the double layer are reduced, $\mathrm{Ag}^{+}+\mathrm{e}^{-} \rightarrow \mathrm{Ag}^{\circ}$. These adatoms can diffuse (diffusion rate depends on the adsorbate complex on the electrode) along the surface and be lost upon incorporation into defect sites. (3) The coverage of various adsorbates is a function of potential. (4) The vibrational frequency of some adsorbates varies with potential as a result of increased covalency between the $\mathrm{Ag}^{\circ}$-molecular bonding with increased excess positive charge on the electrode. (5) Both the SERS intensity and the continuum background increase after one or several ORCs; the amount of increase is initially monotonic with the amount of $\mathrm{Ag}^{+}$reduced on the electrode [60]. (6) Further enhancement can occur with photoreduction of the adherent layer which, according to SEM photographs, affects the topology of the reconstructed Ag surface [11]. (7) Further enhancement can occur during the ORC following rapid hydrogen gas evolution at a negative potential; it is speculated that the $\mathrm{H}_{2}$ bubbles adherent on the electrode affect the topology of the Ag surface during the ORC [61]. (8) Irreversible 1oss of the SERS signa1 occurs when the potential approaches the potential of zero charge (PZC), where the $\mathrm{Ag}$ adatom-adsorbate complexes are dissociated, allowing the Ag adatoms to diffuse and be lost at defect sites $[25,26]$; such irreversible loss is noted to occur also when the temperature is cycled at a fixed potential and is attributed to thermal dissociation of the $\mathrm{Ag}$ adatom-adsorbate complexes [62]. (9) A reversible component of the SERS signal exists with potential cycling or stepping, provided that the most negative potential excursion does not approach 
the PZC, the adatom density is not decreased within a potential range, and the different adsorbate coverages are single-valued functions of the potential (i.e., no hysteresis) [25,26]. (10) Changes in the incident photon energy cause the maximum of the SERS intensity vs potential to shift linearly in the case of pyridine in various electrolytes $[63,64]$; these important results provide rather indisputable evidence that a charge-transfer (CT) excitation mechanism is important and that the resonance between the incident photon energy and the energy levels of the $\mathrm{Ag}^{\circ}-$ adsorbate complexes can be tuned by the potential. (11) The Ago-adsorbate complexes can be complicated or influenced by cations (e.g., $\mathrm{H}^{+}$or $\mathrm{Na}^{+}$) not necessarily in direct contact with the electrode; furthermore, the pyridine and slightly contact adsorbing anions (e.g., $F^{-}$, and $\mathrm{ClO}_{4}^{-}$) can form complexes capable of stabilizing the $\mathrm{Ag}^{\circ}$ adatoms on the surface.

The major weakness in a11 the electrode-related work and, for that matter, a11 the SERS results obtained from different types of substrates is the lack of quantitative information on the enhancement factor associated with several presently proposed mechanisms. The problem is even more complicated because the detected signal is dependent on the molecular coverage on different types of surface sites (e.g., adatoms, submicroscopic, and microscopic) of yet unspecified surface density. Much of the existing electrochemical investigation involves smooth crystalline surfaces [65] while, in order to increase the Raman signal strength, the ORC causes the surfaces to disorder, thereby making the correlation between electrochemistry and SERS studies difficult. The surface coverage of $\mathrm{Cl}^{-}, \mathrm{Br}^{-}$, $\mathrm{I}^{-}, \mathrm{N}_{\overline{3}}$, and $\mathrm{NCS}^{-}$as a function of potential has recently been studied for an electrochemically roughened polycrystalline Ag electrode [66], similar to that used for SERS experiments. From these differential capacitance and kinetic probe measurements, the coverage vs potential curves showed a monotonic decrease as the potential was varied from the most positive value toward the PZC. The coverage vs potential has not been determined for pyridine adsorbed on a polycrystalline roughened Ag electrode. The roughness factor (the electrode surface area divided by the geometric area) has been determined and was found to be $22.5-5$ when these electrodes exhibit intense SERS spectra, implying again that the observed SERS is not due to a $10^{4}-10^{6}$ increase in the surface area [66]. The surface coverage of adsorbed dye molecules (2-amino 5 nitropyridine, ANP) during the SERS measurement has been determined using an optical absorption technique [67]. However, none of the above techniques are sensitive to selective adsorption on different surface topologies. These surface-averaged coverage measurements can therefore provide only partial information needed for qualitative SERS experiments.

In SERS studies with Ag electrodes, the use of dye molecules exhibiting resonance Raman effect in the visible region has started [68]. Energy level shifts as a result of physisorption with the Ag surface are deduced by noting the wavelength difference between the absorption maximum and the Raman excitation maximum. The results for other noble metal electrodes ( $\mathrm{Au}$ and $\mathrm{Cu}$ ) are similar to those for $\mathrm{Ag}$ electrodes [8] and will not be repeated here. The use of foreign metal atoms (e.g., $\mathrm{Cu}$ and $\mathrm{Pb}$ ) deposited on the $\mathrm{Ag}$ electrode (by the under-potential deposition technique, UPD) is present ly being pursued and is extending our understanding of adatom-molecular complexes and SERS studies beyond the coinage metals [10]. Metal alloy $\left(\mathrm{Ag}_{1-\mathrm{x}} \mathrm{Pd}_{\mathrm{x}}\right)$ studies have concluded that SERS is significantly decreased by the larger free electron damping introduced by Pd [69]. SERS spectra of pyridine and $\mathrm{CO}$ adsorbed on electrochemically roughened $\mathrm{Pd}_{1-\mathrm{x}_{\mathrm{x}}} \mathrm{H}_{\mathrm{lec}}$ trodes have also been reported, with emphasis on the critical chemical preparation needed to deposit the Pd ions on the electrode [70]. Very weak Raman spectra of $\mathrm{CO}, \mathrm{I}_{2}$, and phenylhydrazine on Pt electrodes have been reported [71]. Research involving nonaqueous electrolytes is current1y under way [72]. Preliminary results indicate that the excess negative charge on the electrode can be established without $\mathrm{H}_{2}$ gas evolution [72], thereby allowing experimentalists to investigate the specific adsorption characteristics of cations.

Important to SERS deliberations are the recent experimental results of electroreflectance on $\mathrm{Ag}(111)$, (110), and (100) in $0.5 \mathrm{M} \mathrm{NaF}$ electrolytes (F is nearly noncontact adsorbing due to hydration with $\mathrm{H}_{2} \mathrm{O}$ molecules) [73]. The electroreflectance structures are interpreted as electronic transitions from occupied bulk 
Ag electronic levels to vacant surface Ag electronic levels [73]. Such surface levels have been calculated to be within the gaps of the projected bulk density of states and to be above the Fermi energy [74]. The energy difference between these discrete surface leve1s and the broad bulk bands can be tuned by charging the electrode negatively or positively (i.e., varying the potential negative or positive of the PZC). Whether similar electroreflectance structures exist for $\mathrm{Ag}^{\circ}$ adsorbate complexes on roughened SERS active electrodes remains to be investigated.

(d) Films

SERS studies on Ag films are also being actively pursued. Two detailed and up-todate reviews on these investigations have just been completed $[6,7]$. The appealing feature of films is the ability of experimentalists to perform many functions in one UHV chamber, e.g., to evaporate the film on a substrate (of any kind and heated or cooled to any temperature), to expose the film to any one or several gas molecules and, in principle, to simultaneously use other surface physics techniques, such as UPS and EELS. Several research laboratories are already constructing UHV chambers for such multi-purpose surface analyses. At present, however, results on separately performed experiments involving SERS, EELS, and UPS are still being reported.

The SERS experiments [5,7] have been conducted on thick Ag films, films coated on roughened $\mathrm{CaF}_{2}$ [15], thin island films (IF) on smooth substrates at $300^{\circ} \mathrm{K}$ or higher $[20,44]$, thick coldly evaporated films $\left(\mathrm{CEF}, 10^{\circ} \mathrm{K}\right.$ or $\left.150^{\circ} \mathrm{K}\right)$ on smooth substrates $[5,7,14]$, or on IF [16], and films with a gradation of thickness [75]. There is a consensus about many SERS results, but controversies exist on their interpretation, particularly on the relative importance of electromagnetic vs CT models, since submicroscopic and atomic scale roughness has not been quantified on these various films.

There is general agreement concerning the following: (1) Spacer experiments with PMMA [15], oxides of AI [55], and $\mathrm{SiO}_{\mathrm{x}}$ [46] indicate a long range component to SERS, which is different from the enhancement factor for the first layer. (2) Coverage dependence [76] experiments have shown molecular-molecular interaction, causing the excitation profile to shift [6] and some of the SERS intensity and vibrational modes to change (e.g., when $\mathrm{CO}$ is coadsorbed with pyridine) [16]. (3) No enhancement of the substrate (e.g., Si) has yet been detected even though SERS of PNBA coating on top of IF has been readily observed [77]. (4) Temperature quenching of the SERS signal is pronounced in CEF but much less so in IF evaporated at room temperature or above $[6,7,14,16]$. (5) Temperature enhancement is observed (e.g., when cooled to $10^{\circ} \mathrm{K}$, IF and CEF covered with pyridine gave an undetectable signal but SERS was intense upon warming these films to $100^{\circ} \mathrm{K}$ [16]). (6) Molecular specificity is noted (e.g., many organic molecules exhibit strong SERS, but methane, ethane, and propane do not exhibit detectable Raman signals; the SERS of $\mathrm{N}_{2}$ is at least 100 times weaker than $\mathrm{CO}[6,20]$. (7) Metal surface specificity is also noted (e.g., at $90^{\circ} \mathrm{K}$, SERS of CO was observed on CEF but not observed on IF whereas both surfaces exhibited SERS for pyridine [16]; in an analogous experiment, SERS of benzene was absent for terraced Ag(111) but was present for CEF).

(8) Surface topology of the substrate can influence the enhancement factor (e.g., SERS from CEF evaporated on smooth quartz was 10 times weaker than from CEF evaporated on IF [16]).

There are close analogies between evaporation of films and electrochemical reduction of electrodes, as well as between thermal desorption and potential-controlled desorption. The arrival rates and surface diffusion of $\mathrm{Ag}$ atoms are both much slower for the electrochemical case. For both electrodes and films, the adatom diffusion rates are strongly affected by the type of adsorbate, adsorbate coverage, and, of course, temperature. Stabilization of Ag adatoms is constantly present on the electrode in contact-adsorbing electrolytes during the surface reconstruction phase but not present on the film during the evaporation phase. A close parallel exists between thermal-induced quenching or enhancement observed on films and potential-induced quenching or enhancement on electrodes. 
UHV chamber evaporated and exposed films are more amenable to analysis by other well established surface physics techniques. EELS investigation on $\mathrm{CO}, \mathrm{O}_{2}, \mathrm{C}_{2} \mathrm{H}_{4}$, and pyridine exposed $C E F$ was reported to exhibit strong CT peaks while $\mathrm{N}_{2}$-exposed CEF failed to exhibit any CT peaks [78]. Since these EELS peaks were absent on smooth Ag surfaces, it was concluded that the CT excitations are associated with $\mathrm{Ag}$ adatom-molecular complexes which are necessary ingredients for the "chemical" mechanism in SERS. UPS investigation on CEF and on room temperature evaporated film (with and without prolonged RT annealing) indicated that CEF has a greater density of states (due to surface defects) near the top of the d-band, some $4 \mathrm{eV}$ below the bulk Fermi level [79]. Similar results were observed for Ag film ( $3 \AA$ thick) evaporated on a much thicker, room temperature annealed $\mathrm{Ag}$ film cooled to $120^{\circ} \mathrm{K}$ [80]. The observed narrower density of states for these surface defects proportionately decreases the resonant energy denominator associated with CT from the surface defect states at the top of the d-band to the lowest unoccupied orbitals of the $\mathrm{Ag}^{\circ}$-adsorbate complex, an important requirement to increase Raman polarizability. LEED and Auger spectroscopy have been used to insure clean and we11 characterized smooth single-crystal Ag surfaces, (111), (110), and (100), before pyridine molecules are adsorbed at $120^{\circ} \mathrm{K}$. Unlike SERS observations from roughened surfaces, smooth single-crystals yielded Raman signals with the following characteristics [28]: (1) extremely weak, comparable to the free molecuI ar Raman cross section; (2) unshifted symmetric breathing mode at $993 \mathrm{~cm}^{-1}$, instead of at $\sim 1005 \mathrm{~cm}^{-1}$, the usually observed frequency for the first pyridine layer (most likely chemisorbed) on roughened Ag surfaces exhibiting SERS;

(3) comparable intensity for the $\mathrm{C}-\mathrm{H}$ mode at $3050 \mathrm{~cm}^{-1}$, as in the case of pyridine liquid but dissimilar to the usual sERs spectra of pyridine; and (4) polarization sensitive for both the incident (obeying Fresnel equations) and Raman radiation, unlike the totally depolarized situation for SERS spectra.

Future quantitative investigations on clean smooth single-crystal surfaces are essential to our understanding of roughened SERS active surfaces. We must know the precise effect a smooth single-crystal surface has on the Raman polarizability, the symmetry of the scattering tensor, and the electronic levels for both physisorbed and chemisorbed molecules.

IV - CONCLUSION

The realization that SERS can provide molecule and surface site specific information and has the potential of providing a unique in-situ diagnostic probe for surface physics analyses under high pressure gas-solid and 1iquid-solid environments has spurred a rather sustained high level of activity in this field. Some groups are now applying SERS as a diagnostic probe in industrially important areas while others continue to investigate the fundamental problems related to the causes for such large enhancement factors. All these SERS activities may eventually provide a detailed understanding of molecular interactions at surfaces and interfaces in enviromments inaccessible by other surface diagnostic techniques.

\section{$\mathrm{V}$ - ACKNOWLEDGMENTS}

We gratefully acknowledge the partial support of this work by the Army Research office (Grant No. DAAG29-82-K-0040).

\section{REFERENCES}

[1] VAN DUYNE, R.P., in Chemical and Biochemical Applications of Lasers, Vo1. 4, ed. by C.B. Moore (Academic, New York) 1979, p. 101.

[2] CREIGHTON, J.A., in Chemical Physics Series, Vol. 15, ed. by R.F. Willis (Springer, Berlin) 1980, p. 145 .

[3] отто, A., Appl. Surf. Sci. 6 (1980) 309.

[4] Surface Enhanced Raman Scattering, ed. by R.K. Chang and T.E. Furtak (Plenum, New York) 1982 .

[5] WOKAUN, A., Surface Enhanced Electromagnetic Process, Habilitationsschrift, ETZ, 1982, and to be published in Chem. Rev. 
[6] POCKRAND, I., Surface Enhanced Raman Vibrational Studies at Solid/Gas Interfaces, Habilitationsschrift, Universität Düsseldorf, 1983, and to be published in Chemical Physics Series (Springer, Berlin).

[7] 0TTO, A., Surface Enhanced Raman Scattering, Classical and Chemical Origins, to be published in Light Scattering in Solids, Vo1. 4, ed. by M. Cardona and $G$. Giuntherodt (Springer).

[8] CHANG, R.K. and LAUBE, B.L., SERS and Nonlinear Optics Applied to Electrochemistry, to be published in CRC Critical Reviews in Solid State and Material Sciences.

[9] PHILPOTT, M.R., this volume.

[10] PETTINGER, B. and MOERL, L., J. Electron Spectrosc. Related Phenom. 29 (1983) 383.

[11] MACOMBER, S.H., FURTAK, T.E., and DEVINE, T.M., Chem. Phys. Lett. 90 (1982) 439; DEVINE, T.M., FURTAK, T.E., and MACOMBER, S.H., Influence of the Surface Structure of Silver on Surface Enhanced Raman Scattering, to be published in Surf. Sci.; BARZ, F., GORDON II, J.G., PHILPOTT, M.R., and WEAVER, M.J., Chem. Phys. Lett. 91, (1982) 291; CHEN, T.T., VON RABEN, K.U., OWEN, J.F., CHANG, R.K., and LAUBE, B.L., Chem. Phys. Lett. 91 (1982) 494.

[12] ROWE, J.E., SHANK, C.V., ZWEMER, D.A., and MURRAY, C.A., Phys, Rev. Lett. 44 (1980) 1770; ZWEMER, D.A., SHANK, C.V., and ROWE, J.E., Chem. Phys. Lett. 73 (1980) 201.

[13] DORAIN, P.B., VON RABEN, K.U., CHANG, R.K., and LAUBE, B.L., Chem. Phys. Lett. 84 (1981) 405; VON RABEN, K.U., DORAIN, P.B., CHEN, T.T., and CHANG, R.K., Chem. Phys, Lett. 95 (1983) 269.

[14] WOOD, T.H., Phys. Rev. B 24 (1981) 2289; OTTO, A., Phys. Rev. B 27 (1983) 5132; WOOD, T.H., Phys. Rev. B 27 (1983) 5137; WOOD, T.H. and RLEIN, M.V., Solid State Commun. 35 (1980) 263.

[15] MURRAY, C.A., ALLARA, D.L., and RHINEWINE, M., Phys. Rev. Lett. 46 (1981) 57; MURRAY, C.A., in ref. 4., p. 203.; KIRTLEY, J.R., TSANG, J.C., and THEIS, T.N., in ref. 4, p. 223.

[16] SEKI, H., Solid State Commun. 42 (1982) 695; J. Chem. Phys. 76 (1982) 4412; J. Chem. Phys. 76 (1982) 4412; J. Vac. Sci. Technol. 20 (1982) 584 and 18 (1981) 633.

[17] TSANG, J.C., KIRTLEY, J.R., and BRADLEY, J.A., Phys. Rev. Lett. 43 (1979) 772; TSANG, J.C., KIRTLEY, J.R., and THEIS, T.N., Solid State Commun. 35 (1980) 667; SANDA, P.N., WARLAUMONT, J.M., DEMUTH, J.E., TSANG, J.C., CHRISTMANN, K., BRADLEY, J.A., Phys. Rev. Lett. 45 (1980) 1519.

[18] LIAO, P.F., BERGMAN, J.G., CHEMLA, D.S., WOKAUN, A., MELNGAILIS, J., HAWRYLUK, A.M., and ECONOMOU, N.P., Chem. Phys. Lett. 82 (1981) 355; LIAO, P.F. and STERN, M.B., Opt. Lett. 7 (1982) 483; LIAO, P.F., in ref. 4, p. 379.

[19] BLATCHFORD, C.G., CAMPBELL, J.R., and CREIGHTON, 3.A., Surf. Sci. 120 (1982) 435; CREIGHTON, J.A., in ref. 4, p. 315; Surf. Sci. 124 (1983) 209.

[20] MOSKOVITS, M. and DILELLA, D.P., in ref. 4, p. 243; MANZEL, K., SCHULZE, W. and MOSKovits, M., Chem. Phys. Lett. 85 (1982) 183.

[21] (a) OTTO, A., Surf. Sci. 75 (1978) L392; (b) SCHULTZ, S.G., JANIK-CZACHOR, M., and VAN DUYNE, R.P., Surf. Sci. 104 (1981) 419.

[22] BARBER, P.W., CHANG, R.K., and MASSOUDI, H., Phys. Rev. Lett, 50 (1983) 997; Phys. Rev. B 27 (1983) 7251.

[23] MURRAY, C.A., Bul1. Am. Phys. Soc. 28 (1983) 527 and private communication; J. Electron Spectrosc. Rel. Phenom. 29 (1983) 371.

[24] CHANG, R.K. and LONG, M.B., in Light Scattering in Solids II, Topics in Applied Physics, Vol. 50, ed. by M. Cardona and G. Gintherodt (Springer, Heidelberg) 1982, p. 179.

[25] OWEN, J.F., CHEN, T.T., CHANG, R.K., and LAUBE, B.L., Irreversible Loss of Adatoms on Ag Electrodes during Potential Cycling Determined from Surface Enhanced Raman Intensities, to be pub1ished in Surf. Sci.

[26] WEAVER, M.J., BARZ, F., GORDON II, J.G., and PHILPOTT, M.R., Surf. Sci. 125 (1983) 409; PHILPOTT, M.R., BARZ, F., GORDON II, J.G., and WEAVER, M.J., Time Dependence of Surface Enhanced Raman Scattering during and after Oxidation-Reduction Cycles, to be published in J. Electroana1. Chem. 
[27] BLONDEAU, G., CORSET, J., REGIS, A., and JAFFREZIC, N., Thin Solid Films 82 (1981) 97.

[28] CAMPION, A., BROWN, J.K., and GRIZZLE, V.M., Surf. Sci. 115 (1982) L153; CAMPION, A. and MULLINS, D.R., Chem. Phys. Lett. 94 (1983) 576.

[29] TSANG, J.C., AVOURIS, PH., and KIRTLEY, J.R., Chem. Phys. Lett. 94 (1983) 172.

[30] UGADAWA, M., CHOU, C.-C., HEMMINGER, J.C., and USHIODA, S., Phys. Rev. B 23 (1981) 6843.

[31] VON RABEN, K.U., CHANG, R.K., and LAUBE, B.L., Chem. Phys. Lett. 79 (1981) 465; VON RABEN, K.U., CHANG, R.K., LAUBE, B.L., and BARBER, P.W., Wavelength Dependence of Surface Enhanced Raman Scattering from Ag Co11oids with $\mathrm{CN}^{-}$, Pyridine, and $\mathrm{SO}_{2}$ Adsorbates, submitted to Surf. Sci.

[32] MESSINGER, B.J., VON RABEN, K.U., CHANG, R.K., and BARBER, P.W., Phys. Rev. B 24 (1981) 649; KERKER, M., WANG, D.-S., CHEW, H., SIIMAN, 0., and BUMM, L.A., in ref. 4 , p. 109.

[33] KERKER, M., SIIMAN, 0., BUMM, L.A., and WANG, D.-S., App1. Opt. 19 (1980) 3253.

[34] WETZEL, H. and GERISCHER, H., Chem. Phys. Lett. 76 (1980) 460.

[35] WOOD, D.M. and ASHCROFT, N.W., Phys. Rev. B 25 (1982) 6255.

[36] JHA, S.S., in ref. 4, p. 129; AGARWAL, G.S. and JHA, S.s., Phys. Rev. B 26 (1982) 4013.

[37] AYRA, K. and ZEYHER, R., Phys. Rev. B 24 (1981) 1852; Theory of Surface Enhanced Raman Scattering, to be published in Light Scattering in Solids, Vo1. 4, ed. by M. Cardona and G. Güntherodt (Springer, Berlin).

[38] BENNER, R.E., VON RABEN, K.U., LEE, K.C., OWEN, J.F., CHANG, R.K., and LAUBE, B.L., Chem. Phys. Lett. 96 (1983) 65.

[39] KRASSER, W. and RENOUPREZ, A.J., Solid State Commun. 41 (1982) 231.

[40] BACHACKASHVILlI, A., EFRIMA, S., KATZ, B., and PRIEL, z., Chem. Phys. Lett. 94 (1983) 571.

[41] LIPPITSCH, M.E., Chem. Phys. Lett. 74 (1980) 125 and 79 (1981) 224.

[42] JEANMAIRE, D.L. and VAN DUYNE, R.P., J. Electroanal. Chem. 84 (1977) 1.

[43] GLASS, A.M. LIAO, P.F., BERGMAN, J.G., and OLSON, D.H., Opt. Lett. 5 (1980) 368.

[44] RITCHIE, G. and CHEN, C.Y., in ref. 4, P. 361; RITCHIE, G. and BURSTEIN, E., Phys. Rev. B 24 (1981) 4843.

[45] WEITZ, D.A., GAROFF, S., HANSON, C.D., GRAMILA, T.J., and GERSTEN, J.I., J. Iumin. 24/25 (1981) 83; WEITZ, D.A., GAROFF, S., GERSTEN, J.I., and NITZAN, A., J. Chem. Phys. 78 (1983) 5324; J. Electron Spectrosc. Re1. Phenom. 29 (1983) 363; WEITZ, D.A., GAROFF, S., and GRAMILA, T.J., Opt. Lett. 7 (1982) 168.

[46] WOKAUN, A., LUTZ, H.-P., KING, A.P., WILD, U.P., and ERNST, R.R., Energy Transfer in Surface Enhanced Luminescence, to be published.

[47] ABE, H., MANZEL, K., SCHULZE, W., MOSKOVITS, M., and DILELLA, D. P., J. Chem. Phys. 74 (1981) 792; DILELLA, D.P. and MosKoviTS, M., J. Phys. Chem. 58 (1981) 2042.

[48] SCHULZE, W., BECKER, H.U., and LEUTLOFF, D., J. Phys. (Paris) C2 (1977) 7; SCHULZE, W., BECKER, H.U., and ABE, H., Ber. Bunsenges. Phys. Chem. 82 (1978) 138.

[49] SCHULZE, W., BECKER, H.U., MINKWITZ, R., and MANZEL, K., Chem. Phys. Lett. 55 (1978) 59.

[50] TEVAULT, D.E. and SMARDZEWSKI, R.R., J. Chem. Phys. 77 (1982) 2221.

[51] SCHULZE, W. and MOSKOVITS, M., unpublished results.

[52] WOKAUN, A., GORDON, J.P., and LIAO, P.F., Phys. Rev. Lett. 48 (1982) 957.

[53] VON RABEN, K.U., private communication.

[54] LIAO, P.F. and STERN, M.B., Opt. Lett. 7 (1982) 483.

[55] ALLARA, D.L., MURRAY, C.A., and BODOFF, S., Bu11. Am. Phys. Soc. 26 (1981) 338.

[56] WOKAUN, A., BERGMAN, J.G., HERITAGE, J.P., GLASS, A.M., LIAO, P.F., and OLSON, D.H., Phys. Rev. B 24 (1981) 849.

[57] MURPHY, D.V., VON RABEN, K.U., CHANG, R.K., and DORAIN, P.B., Chem. Phys. Lett. 85 (1982) 43. 
[58] CHEN, C.K., HEINZ, T.F., RICARD D., and SHEN, Y.R., Phys. Rev. Lett. 46 (1981) 1010; HERITAGE, J.P. and GLASS, A.M., in ref. 4, p. 391.

[59] FLEISCHMANN, M. and HILL, I.R., in ref. 4, p. 275.

[60] PETTINGER, B. and WETZEL, H., in ref. 4, p. 293.

[61] BARZ, F., GORDON II, J.G., PHILPOTT, M.R., and WEAVER, M.J., Chem. Phys. Lett. 94 (1983) 168.

[62] MACOMBER, S.H. and FURTAK, T.E., Solid State Commun. 45 (1983) 267.

[63] BILLMANN, J. and OTTO, A., Solid State Commun. 44 (1982) 105.

[64] FURTAK, T.E. and MACOMBER, S.H., Chem. Phys. Lett. 95 (1983) 328.

[65] VALETTE, G., HAMELIN, A., and PARSONS, R., Z. Phys. Chem. (Frankfurt am Main) 113 (1978) 71.

[66] LARKIN, D., GUYER, K.L., HUPP, J.T., and WEAVER, M.J., J. Electroanal. Chem. 138 (1982) 401 .

[67] BUSBY, C.C. and CREIGHTON, J.A., J. Electroanal. Chem. 133 (1982) 183.

[68] BLATCHFORD, C.G., CAMPBELL, J.R., and CREIGHTON, J.A., Surf. Sci. 108 (1981) 411; CAMPBELL, J.R. and CREIGHTON, J.A., J. Electroana1. Chem. 143 (1983) 353.

[69] FURTAK, T.E., and KESTER, J., Phys. Rev. Lett. 45 (1980) 1652.

[70] FLEISCHMANN, M., GRAVES, P.R., HILL, I.R., and ROBINSON, J., Chem. Phys. Lett. 95 (1.983) 322 .

[71] COONEY, R.P., FLEISCHMANN, M., and HENDRA, P.J., J. Chem. Soc. Chem. Commun. (1977) 235; COONEY, R.P., REID, E.S., HENDRA, P.J., and FLEISCHMANN, M. , J. Am. Chem. Soc. 99 (1977) 2002; HEITBAUM, J., Z. Phys. Chem. 105 (1977) 307.

[72] VAN DUINE, R.P., private communication.

[73] BOECK, W. and KOLB, D.M., Surf. Sci. 118 (1982) 613.

[74] HO, K.-M., HARMON, B.N., and LIU, S.H., Phys. Rev. Lett. 44 (1980) 1531; KOLB, D.M. , BOECK, W., HO, K.-M., and LIU, S.H., Phys. Rev. Lett. 47 (1981) 1921.

[75] BERGMAN, J.G., CHEMLA, D.S. LIAU, P.F., GLASS, A.M., PINCZUK, A., HART, R.M., and OLSON, D.H., Opt. Lett. 6 (1981) 33; GLASS, A.M., WOKAUN, A., HERITAGE, J.P., BERGMAN, J.G., LIAO, P.F., and OLSON, D.H., Phys. Rev. B 24 (1981) 4906; HERITAGE, J.P. and GLASS, A.M. , in ref. 4, p. 391.

[76] SANDA, P.N., DEMUTH, J.E., TSANG, J.C., and WARLAUMONT, J.M., in ref. 4, p. 189.

[77] LYON, S.A. and WORLOCK, J., Bu11. Am. Phys. Soc. 26 (1981) 378.

[78] SCHMEISSER, D., DEMUTH, J.E., AVOURIS, PH., Chem. Phys. Lett. 87 (1982) 324.

[79] EICKMANS, J., GOLDMANN, A., and OTTO, A., to be pub1ished in Surf. Sci.

[80] KOCH, E.E., BARTH, J., FOCK, J.H., GOLDMANN, A., and OTTO, A., Solid State Commun. 42 (1982) 897. 